\title{
Perspectives of Usage of Seamless and Fiber Basalt Filament for Construction and Rehabilitation of Motor Roads and Airfields
}

\author{
Kateryna Krayushkina (D) 1*, Andrii Bieliatynskyi \\ ${ }^{I}$ Department of Interiors Design, National Aviation University, 03058, Kiev, Ukraine \\ ${ }^{2}$ Department of Reconstruction Roads and Airfields, National Aviation University, 03058, Kiev, Ukraine
}

Received 02 February 2020; accepted 31 March 2020

\begin{abstract}
In recent years, the number of heavy vehicles has increased on the roads of Ukraine. But coatings that were built long ago and according to the old standards do not withstand overhauls. This leads to premature destruction of the road structure, which is also facilitated by negative weather factors. One of the ways to increase the durability of roads is the use of dispersed and directional reinforcement with basalt materials. The article presents the results of studies on the use of basalt materials for reinforcing asphalt concrete and concrete coatings of aerodrome roads.
\end{abstract}

Keywords: fibers, crack, asphalt, concrete, reinforced, pavement, grids, road construction.

\section{Introduction}

Modern motor roads and airfields are a complicated complex of engineering structures that are under the influence of heavy dynamic loads from traffic, adverse climatic conditions and require the provision of safe all year-round traffic conditions for motor vehicles and aircrafts.

Throughout the year, road and airfields must be durable, even, rough and withstand dynamic loads of motor traffic.

Over a long period of time, the road transportation volumes have outpaced the rates of construction of roads with rigid pavement that resulted in the critical growth in traffic volume on the roads (Krayushkina et al., 2012).

The article presents data on the results of the conducted research on the use of reinforcing layers made of materials based on basalt continuous fibers $(\mathrm{BCF})$ for the directional reinforcement of asphalt and concrete pavement of roads and airfields. The main reinforcing materials used are grids, canvases, basalt-plastic reinforcement and composite materials (grid with non-woven substrate) (Krayushkina \& Belyatynsky, 2013; Krayushkina \& Khimerik, 1998).

Continuous fibers from basalt rocks are known to have sufficiently high strength characteristics, chemical and thermal resistance. Therefore, BCFs provide the necessary physical and mechanical characteristics of both chopped fibers and other items - grids and canvases which have been widely used in the last decade (Moskaleva, 2014; Gamelyak, 2010).

Their use in the structures of road and airfield pavements allows increasing the resistance of all layers and especially the of pavement to the impact of traffic loads, weather and climatic factors, increasing the inter-repair periods and operational characteristics, reducing the consumption of materials in the construction and repair of roads.

The fibers used in fiber reinforced concrete, include various metal and non-metal fibers. Non-metal fibers typically include glass, polyamide, asbestos and basalt. A combination of different fiber types has also been applied to maximize the benefits (Tapkin \& Özcan, 2012).

In addition to direct reinforcement, composite basalt products were used in Ukraine in the form of: profiles, bumpers of safety barriers and lighting pillars, road signs to replace traditional metal products.

Several types of basalt fibers are available depending on the diameter and are divided into the following categories: micro-thin, ultrathin, superthin, thin, thickened and rough (Ferrotti et al., 2014; Ye \& Li, 2016).

Ukraine occupies one of the leading places in the world for basalt reserves. The presence of a base of an unlimited cheap raw material makes it possible to create economical products that compete in value with imported counterparts. Given the high material capacity of the road industry and high physical and chemical properties of the products obtained, the urgency of using the basalt reinforcing layers is, undoubtedly, high (Krayushkina et al., 2005; Krayushkina, 2001).

${ }^{*}$ Corresponding author. E-mail: ekrayushkina15@ukr.net 
The asphalt pavement sustains multiple cyclic traffic loads, opposes tensions that appear in the pavement layer as a result of variations in temperature and due to systematic freezing. With the introduction of reinforcing fibers in asphalt concrete, these qualities have shown to improve to various degrees (Dzihigiris \& Mahova, 2002; Füssl et al., 2015a, 2015b; Wilmers \& Veplar, 1994; Kokodeeva, 2014).

A similar situation occurred at airfields, where an increase in the number of heavy duty aircraft led to a mismatch in the operational characteristics of existing runways.

The vast majority of motor roads in Ukraine are asphalt pavement roads, that is why the issue of increasing their durability is the most topical. For airfields, the main structural materials are asphalt and cement concrete. Currently, road and airfield pavement are constructed using traditional road-building materials that do not provide a standard service life.

The lifetime of these structures depends on the strength, stability and durability of the individual structural layers (Gameliak et al., 2010).

Most often, the destruction begins with the deterioration of the pavement, as it is directly loaded and affected by adverse weather and climatic factors (Mueller-Rochholz, 2010).

The causes of the deterioration of road and airfield pavements can be roughly divided into two large groups: the deterioration of the pavement itself with a sufficiently strong base, as well as deformation and destruction of the pavement which are associated with the loss of strength of the road foundation.

Asphalt concrete and cement concrete are the main structural materials, however, they have disadvantages, which are difficult to eliminate by traditional methods (Ferrotti et al., 2014; Korolev, 1994).

The way of improving the performance of asphalt concrete, such as insufficient shear resistance at high temperatures, leading to the formation of waves, rutting; low tensile strength which contributes to the reduction of crack resistance; and in case of cement concrete - high brittleness at fracture and low deformability at bending includes a fundamentally new method of altering the pavement structure - introducing a reinforcing layer in the form of grids or modern canvass.

\section{Research of the roads state}

The study of the roads state of the central part of Ukraine revealed the main types of deformations in Kyiv and Chernihiv regions areas:

- chipping, scaling, potholes;

- longitudinal and transverse cracks, aligatoring;

- waves, sags, shears.

The characteristics of the state of the studied of the roads areas are shown in Table 1.

Table 1. Characteristics of the state of roads areas I-III of technical categories of the central part of Ukraine

\begin{tabular}{|l|c|c|c|c|c|c|}
\hline \multirow{2}{*}{ Name of the road } & \multirow{2}{*}{$\begin{array}{c}\text { Number of } \\
\text { surveyed test } \\
\text { sites length, km }\end{array}$} & $\begin{array}{c}\text { Average } \\
\text { lifetime, }\end{array}$ & Technical & year & & \multicolumn{2}{|c|}{ Damaged areas, \% of total pavement area } \\
\cline { 5 - 7 } & & & $\begin{array}{c}\text { Chippings, } \\
\text { scaling, potholes }\end{array}$ & $\begin{array}{c}\text { Longitudinal, } \\
\text { transverse cracks }\end{array}$ & $\begin{array}{c}\text { Waves, sags, } \\
\text { shears }\end{array}$ \\
\hline Kyiv-Odesa & $10 / 3840$ & 6.5 & I & $1.1-2.2$ & $2-4$ & $1.5-2.5$ \\
\hline Kyiv-Zhytomyr & $8 / 2520$ & 5.0 & I & $8.5-10.5$ & $6-8$ & $3-5$ \\
\hline Kyiv-Chernihiv & $12 / 4200$ & 2.5 & II & $4.2-6.2$ & $8.0-12.0$ & $2.0-4.0$ \\
\hline Chernihiv-Slavutich & $6 / 2200$ & 8.4 & III & $5.0-8.0$ & $6.0-20.0$ & $5.0-10.0$ \\
\hline Kipti-Hlukhiv-Bachivsk & $8 / 2950$ & 3.0 & II & $3.0-5.0$ & $7.0-10.0$ & $8.0-12.0$ \\
\hline
\end{tabular}

The survey showed that the pavement of most roads is damaged by cracks of 5-6 cm deep and 3-8 mm wide, located approximately perpendicular to the axis of the road.

The dynamics of crack formation by months of the year is shown in Figure 1.

Site surveys were carried out in October, December, February, April and July, i.e. during the most typical periods of temperature changes.

The results of observations of crack formation show that in summer the cracks do not close, although their number decreases. In the period of spring freezing - thawing, the cracks propagation is relatively the same as during the period of maximum low temperatures; and only in July the cracks partially close. Performed studies allowed developing a classification of the process of crack formation. In the course of operation, three types of cracks are formed within the pavement structure:

I - reflected cracks up to $3.0 \mathrm{~cm}$ in size, distributed over the length with the distance of $35-45 \mathrm{~cm}$ from each other. These cracks originate during the first winter of operation and in the further years they develop in depth and width. 


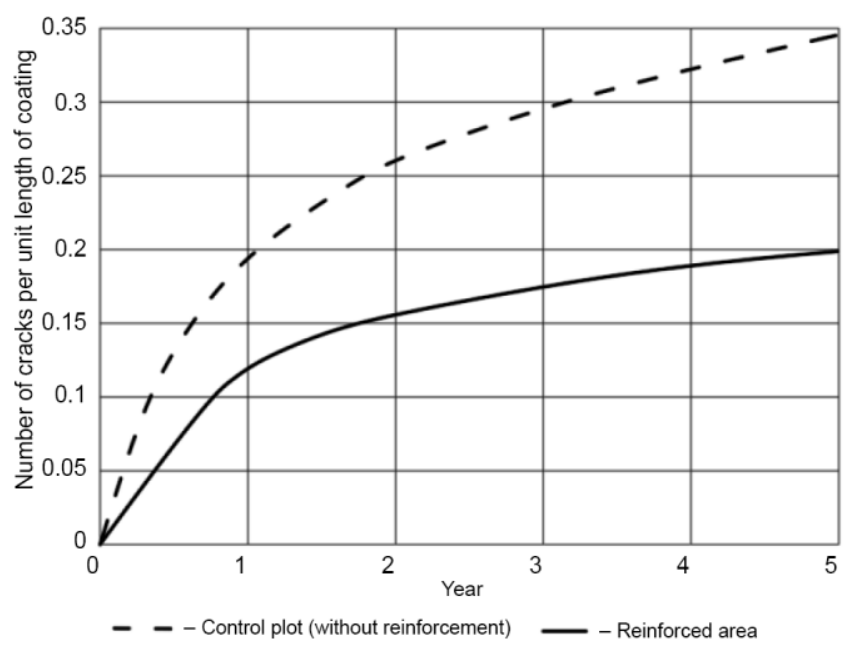

Figure 1. Dynamics of crack formation

II - temperature cracks up to $1.5 \mathrm{~cm}$ in size, distributed over the length with the distance of $10-20 \mathrm{~m}$ from each other. These cracks are formed during 2-3 years of operation.

III - fatigue - temperature cracks, up to $0.3 \mathrm{~cm}$ in size, distributed over the length with the distance of 2.5-3.0 $\mathrm{m}$ from each other. These cracks are formed during 3-5 years of operation.

The presence of cracks adversely affects the amount of moisture accumulation in the soil due to much higher surface moisturizing.

The results of the conducted research and the existing experience of application of reinforcing grids in road structures show that reinforcement significantly reduces crack resistance of pavement and produces a positive effect on the water-thermal regime of the subgrade thereby eliminating the infiltration of precipitation into the soil. This increases the strength of asphalt concrete to tensile forces impact and the effect of horizontal loads. Reinforcement of asphalt concrete with basalt grid increases its tensile strength by at least $50 \%$ while reducing the deformation at rupture by $65 \%$. Crack resistance increases by $35-40 \%$ compared to non-reinforced pavement material (Gameliak et al., 2010; Korolev, 1994).

Studies have shown that asphalt concrete reinforced with a grid has a much greater shear resistance than conventional asphalt concrete and resistance to cracking (the most common defect in asphalt concrete pavements which is almost impossible to provide using traditional technologies).

At negative temperatures, asphalt concrete goes from plastic to elastic and even solid brittle state. With rapid changes in the positive temperature to the negative tensile stresses occur in asphalt causing the initiation of temperature cracks on the surface, the number of which increases over time.

These cracks are located across the roadway at the distance of 6-8 meters. The formation of cracks is caused by a decrease in the deformation ability of asphalt concrete at a negative temperature. The presence of temperature cracks in the asphalt reduces the service life of the pavement, as the water infiltration gradually destroys the asphalt concrete itself, as well as the underlying layers of road pavement. In the case of the formation of through cracks in the pavement, the calculated performance scheme of the pavement as regards the load from the wheels of cars, sharply changes. As a result, considerable dynamic and even hydrodynamic loads result in the complete failure of the entire road pavement. The higher the traffic volume, the faster the wear of the pavement is.

It is possible to increase the crack resistance of asphalt concrete by two fundamentally different methods: to increase the deformability of asphalt concrete or to increase the tensile strength of asphalt concrete. It is possible to increase the deformability of asphalt concrete by stabilizing the properties of organic binder (bitumen) with various additives. However, it is most effective to increase the crack resistance of asphalt concrete by increasing the tensile strength of asphalt concrete by means of its reinforcement. Currently, reinforcement is most often done using synthetic grids. The use of reinforced asphalt concrete with a basalt grid showed that the tensile strength of reinforced asphalt concrete increased by at least 50\%, while reducing the tensile strength by $65 \%$ and the crack resistance by 35-40\% higher than the non-reinforced non-rigid pavement (Gameliak et al., 2010; Korolev, 1994).

Figure 2 shows the survey data for the road section of Kiev-Odesa highway for 5 years, reinforced with BG-1 (basalt grid). The grid was laid between the layers of asphalt concrete. The thickness of the top layer is $5 \mathrm{~cm}-\mathrm{of} \mathrm{hot}$ fine-grained asphalt concrete type "B". 


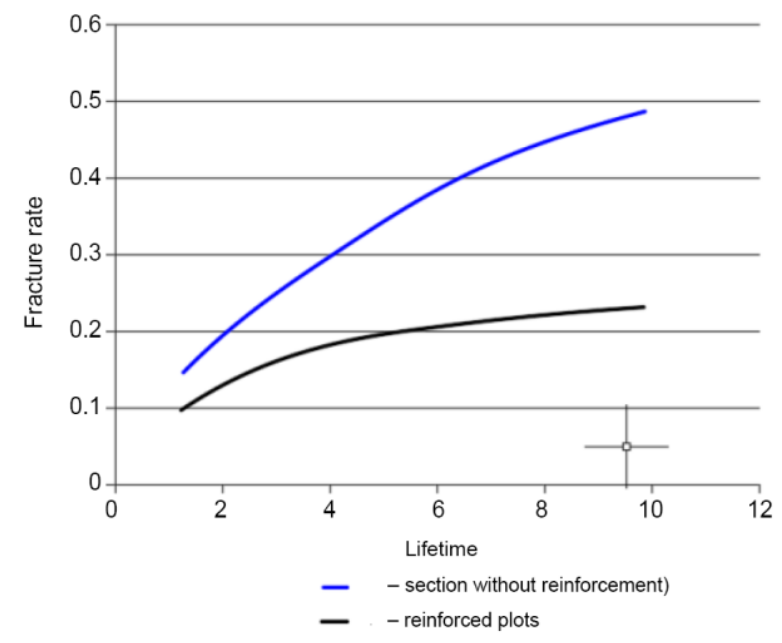

Figure 2. Dynamics of cracks propagation on the section with reinforced pavement

It is determined that the index of the operational state of asphalt pavements is fracturing which is characterized by the fracturing index (Korolev, 1994):

$$
I C=\frac{\sum T_{p}+\sum T_{p r}+\sum T_{k}}{1000}\left(\mathrm{~m} / 1000 \mathrm{~m}^{2}\right),
$$

where $T_{p}, T_{p r}, T_{k}$ - is the length of the longitudinal, transverse and oblique cracks, respectively.

\section{Reinforcement of asphalt concrete pavements}

To establish the correlation between the reinforcement coefficient and the fracturing of the pavement, the results approximation of the study of the pavement cracking of the test areas was carried out (Figure 3 ) depending on their service life.

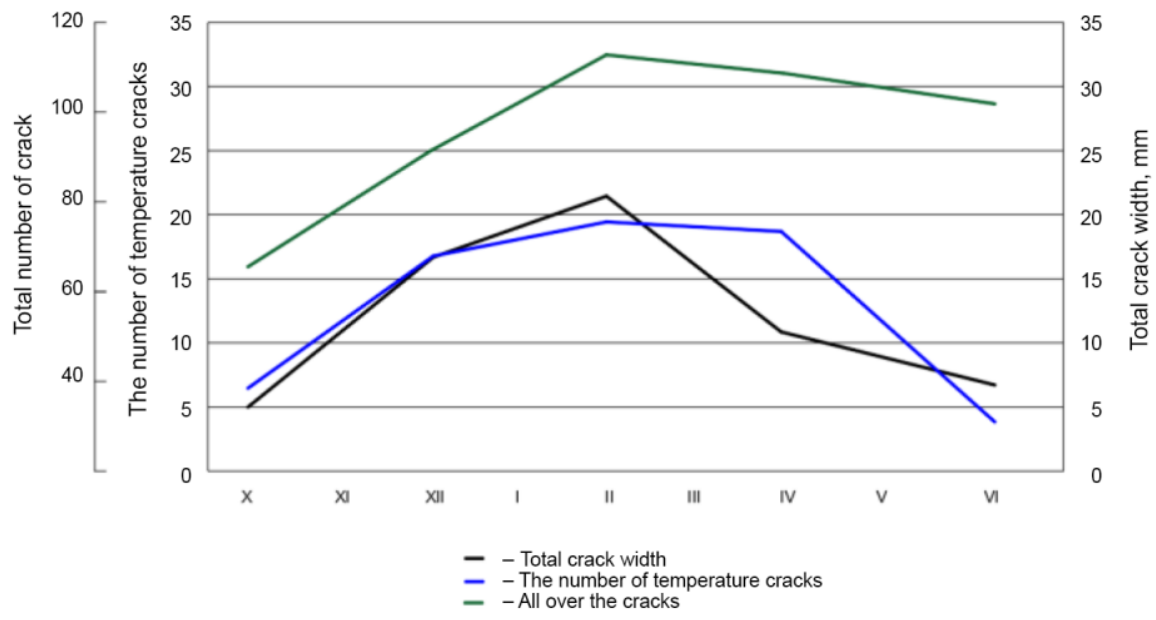

Figure 3. Analysis of fracturing changes of asphalt pavement

As can be seen from Figure 3, in the areas with reinforced pavement, the formation of cracks is much slower and practically does not increase after 4 years of service, unlike in case of non-reinforced pavement.

Thus, effective measures that increase the operational reliability of roads with asphalt pavement should provide an increase of corrosion resistance and crack resistance by the reinforcement with geosynthetic materials.

It is established that the effect of fracturing on the moisture accumulation of the soil is approximated by dependence (Figure 4):

$$
W=-0.397 e^{-1.584 n}+1.058
$$

where: $n$ - is the fracturing index, dimensionless; $W$ - is relative humidity of soil during the calculation period.

When analyzing this dependence, it is obvious that an increase in the fracturing of the pavement leads to an increase in the moisture accumulation in the soil of the subgrade, which, over time, affects the appearance of free water in the lower layers of the road structure. All this leads to the general destruction of the road structure. 


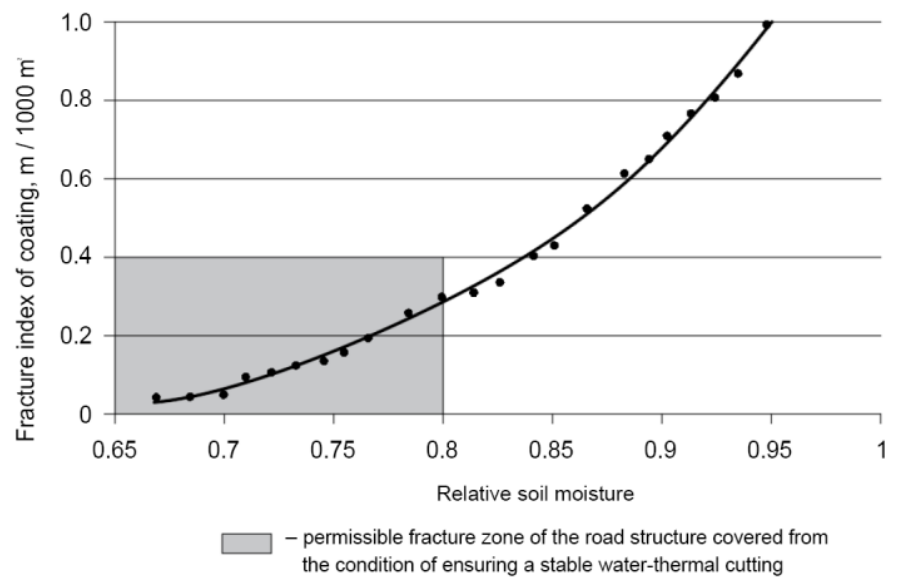

Figure 4. The influence of the state of asphalt pavement on the value of soil moisture accumulation of soil, $\mathrm{m}^{2}$

The study of the dynamics of crack formation in the test sections allowed establishing the regularities due to the specifics of natural and climatic conditions: uneven swelling of soil of the subgrade and destructive temperature regime, especially in the period of thawing of the road structure (number of freezing cycles - over 70).

On the basis of the conducted research, the model of reduction of negative influence of natural and climatic factors on providing the highways performance reliability in conditions of Ukraine was developed (Figure 5).

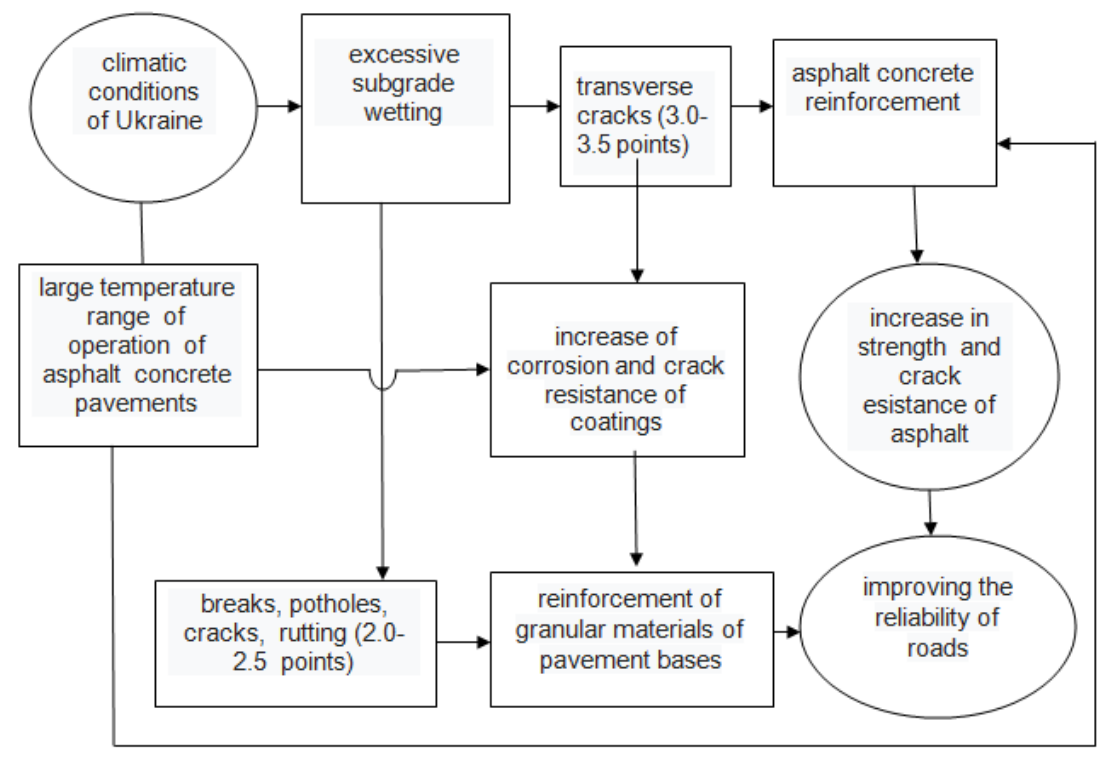

Figure 5. A model for reducing the destructive effects of natural and climatic conditions to improve the highways performance reliability

Complex tests of BG-1 road nets based on BCF have been conducted in Ukraine since the beginning of the 21st century. With their use, the construction of a section of the roads Kyiv-Odesa, Kyiv-Chop was carried out.

Tests confirmed the effectiveness of the use of basalt grids in road construction. Preliminary calculations, application practice and foreign experience show that the use of these grids reduces the occurrence of cracks, sags, potholes on the pavement.

The combination of these positive factors can significantly increase the durability of asphalt pavements. The estimated cost of the reinforced pavement is approximately 20-30\% higher than that of the non-reinforced one. But the service life of the reinforced pavements is not less than in 1.5 times higher than the traditional one. Given the cost of maintaining and repairing the road during the service life, the actual cost of using the reinforced asphalt is reduced by $6 \%$. In addition, environmental aspects of the problem must be taken into account. Bad quality pavements sharply decrease motor vehicle traffic speeds and, consequently, increase exhaust emissions. During repair works in the cities, it is necessary to close separate sections of streets with the redirection of traffic flows to other streets that creates additional environmental burden on them. Reducing the amount of exhaust gas gives rise to an additional cost-effective but significant enough economic effect, especially in urban areas. 


\section{Reinforcement of cement concrete pavements}

Cement concrete pavements must withstand repeated cyclic traffic loads, resist the stresses arising in the road surface from fluctuations in temperature and humidity, as well as from the systematic freezing and thawing of water in the pores of cement concrete, and withstand stresses resulting from the plate's deformation.

To determine the possibility of using the basalt grid and the canvas as a reinforcing material for concrete pavements of roads and airfields, it was necessary to study the resistance of basalt fiber BCF to moisture, chemical compounds and durability in the solution of Portland cement.

For concrete pavements it is possible to use both, the BG-1 grid and the solid BCC canvas. However, experience shows that the most effective use is BCC, so the studies were conducted with a continuous interlayer.

The stability of the basalt continuous layer of BCC to the water impact was studied by changing the tensile strength after keeping the samples in $\mathrm{H}_{2} \mathrm{O}, \mathrm{CaO}$ solutions $-1.0 \mathrm{~g} / 1, \mathrm{~K}_{2} \mathrm{O}-2.0 \mathrm{~g} / 1, \mathrm{NaO}-2.0 \mathrm{~g} / 1, \mathrm{SO}_{3}-2.8 \mathrm{~g} / 1$ for 5 days.

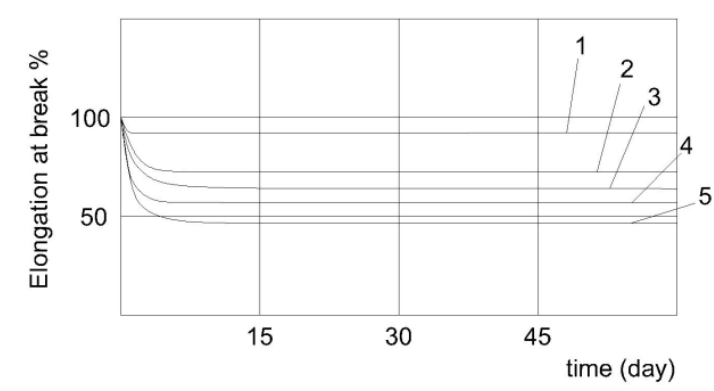

$1-\mathrm{H}_{2} \mathrm{O} ; 2-\mathrm{CaO} ; 3-\mathrm{K}_{2} \mathrm{O} ; 4-\mathrm{NaO} ; 5-\mathrm{SO}_{3}$

Figure 6 . The dependence of tensile strength change (\% of the original) on the keeping time of the basalt continuous interlayer of BCC in different solutions

When analyzing the data in Figure 6, it can be seen that BCF-based materials are water- and chemical-resistant products. The impact of water practically does not reduce the strength and the impact of chemicals reduces it by 20-30\% and only in the first 5 days. Then the values stabilize. Thus, it can be argued that BCF products should be used for the lower layers of pavement and for reinforcing the foundation of airfields.

In the airfield construction, basalt fiber grids have proved positive effect when placing them between the layers of concrete when arranging a two-layer cement-concrete pavement.

Such pavements are placed by concrete using the method of splicing when arranging the lower layer of conventional concrete, and the upper - of high strength. The upper layer of high-strength concrete is arranged of 6-7 cm thick from rigid mixtures with a stiffness of 80-100 MPa.

During laboratory studies, the authors have defined that laying a basalt grid between the layers allows increasing the tensile strength at bending of the upper layer in 2-4 times. At the same time, high-strength concrete can be made without air-tightening additives with providing the necessary frost resistance.

Basing on the laboratory data and the results of production implementation on the roads of Ukraine, the data were obtained on the change in strength of the upper and lower layers of concrete, depending on the thickness of the upper layer in the presence of basalt grid and without it, as shown in Table 2.

Table 2. Change in the strength of concrete two-layer pavement at the reinforcement with the basalt grid

\begin{tabular}{|c|c|c|c|c|}
\hline \multirow{2}{*}{$\begin{array}{c}\text { The thickness of the } \\
\text { top layer, cm }\end{array}$} & \multicolumn{2}{|c|}{ Reinforced pavement } & \multicolumn{2}{c|}{ Non-reinforced } \\
\cline { 2 - 5 } & $\begin{array}{c}\text { Tensile strength at } \\
\text { bending Ru, MPa }\end{array}$ & $\begin{array}{c}\text { Compressive strength, } \\
\text { Rst, MPa }\end{array}$ & $\begin{array}{c}\text { Tensile strength at } \\
\text { bending, MPa }\end{array}$ & $\begin{array}{c}\text { Compressive } \\
\text { strength, Rst, MPa }\end{array}$ \\
\hline 4 & 5.2 & 41 & 3.6 & 36.0 \\
\hline 5 & 9.0 & 45 & 4.3 & 39.5 \\
\hline 6 & 16.5 & 54 & 5.6 & 44.7 \\
\hline 7 & 17.4 & 72 & 7.5 & 50.5 \\
\hline 8 & 21.5 & 85 & 8.1 & 54.5 \\
\hline
\end{tabular}

Note: tensile and compressive strength values are given for two-layer pavement.

Analysis of the data in Table 2 shows that the presence of a grid has a positive effect on the structure of the layers of concrete. Here is the complete splicing due to the physico-chemical interaction of the basalt fibers with the surface of the grains of cement stone aggregate and the formation of so-called bonding layers with a strong structure. 
That is, the basalt layer works similarly to the reinforcement in the manufacture of precast concrete slabs in the factory.

This strengthening is also the result of increasing the dispersion and compaction of the cement stone due to the directional arrangement of the fiber grid interlayer which has excess surface energy at the interface between the layers of concrete.

The physicochemical properties of the BG-1 basalt grid and the BCC fiber based fabric are shown in Table 3.

Table 3. Specifications of basalt fiber grid and fabric

\begin{tabular}{|l|c|c|}
\hline \multicolumn{2}{|c|}{ BG-1 } & \multicolumn{2}{c|}{ Properties } \\
\hline \multirow{2}{*}{ Breaking load not less than, $\mathrm{kg}$} & by width & 120 \\
\cline { 2 - 3 } & by length & 250 \\
\hline Density, $\mathrm{g} / \mathrm{m}^{2}$ & & $1-1.5$ \\
\hline Elongation under load, \% & & \\
\hline The impregnation of the grid with a special composition ensures its rigidity, non-combustibility, acid and alkaline resistance \\
\hline BCC & & 600 \\
\hline Breaking load not less than, $\mathrm{kg}$ & by width & 600 \\
\cline { 2 - 3 } & by length & \\
\hline
\end{tabular}

In addition to the characteristics specified in Table 3, BCF products have high tensile strength, modulus of elasticity and insignificant change under load. In addition, it should be noted that the tensile strength ranges from 200 to $1200 \mathrm{MPa}$, the modulus of strain of the basalt fibers reaches $80 \mathrm{GPa}$. Temperature range of application of basalt materials - from 200 to $700{ }^{\circ} \mathrm{C}$, softening point $-750{ }^{\circ} \mathrm{C}$, sintering $-1050{ }^{\circ} \mathrm{C}$. The mechanical properties of the material are not sensitive to temperatures up to $200^{\circ} \mathrm{C}$.

Comparison of the degree of influence of basalt grid BG-1 and solid canvas of BCC on the strength of cement concrete is shown in Figure 7.

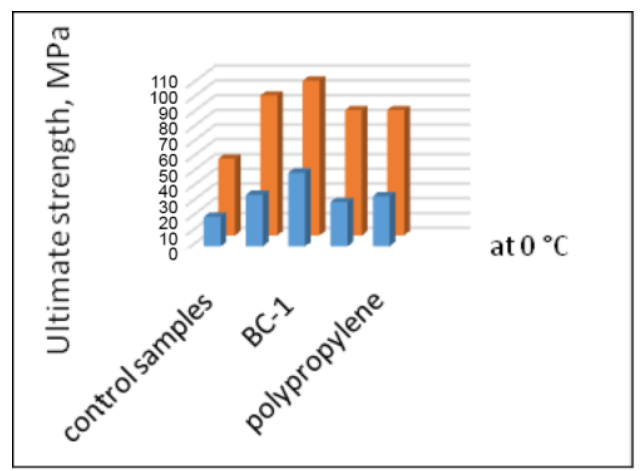

Figure 7. Research results of concrete specimens reinforced with basalt grid and canvass

As can be seen from the above data, the use of BCF significantly increases the effect of reinforcement at both low and high temperatures. If the tests of non-reinforced samples increase in strength is $10-14 \%$, then due to the reinforcement their increment is $20-26 \%$.

The main purpose of these materials is road and airfield construction, which are shown in Figures 8 and 9.

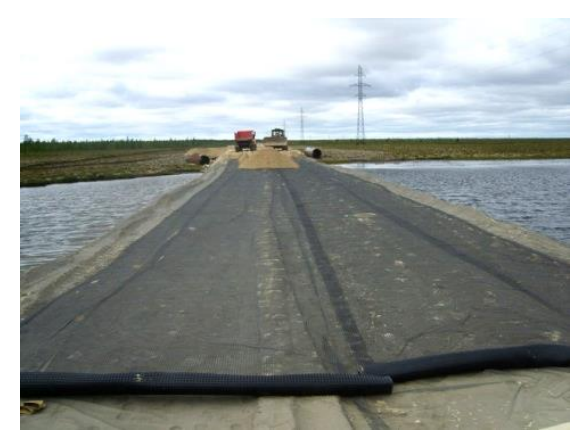

Figure 8. Application of basalt grids in road construction

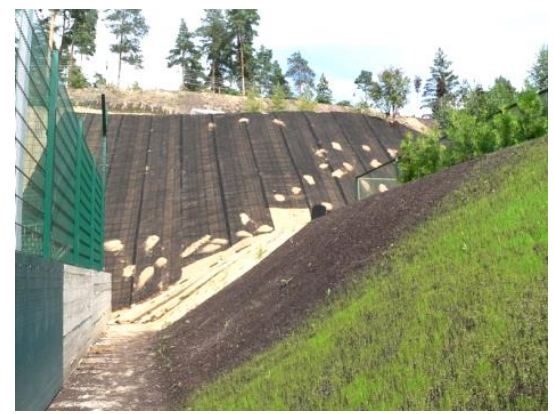

Figure 9. Reinforcement of embankments by road grids 
Geotextile materials from the BCF have the prospect of widespread use in hydraulic engineering, prerecultivation and erosion protection, anti-landsliding and other works.

Grass, bushes and trees sprout through the placed and fixed BCF grid. This method of reinforcement is the most effective, not expensive, meets the environmental requirements.

\section{Basalt-plastic reinforcement, profiles and composite products for road construction}

In addition to the above data, Ukraine uses products made of basalt materials for roads and airfields, namely: basalt reinforcement, cable fences to ensure traffic safety, anchors for tunnels.

Basalt-plastic reinforcement (BPR) is used for reinforcement of concrete pavements, tunnels, bridges. In this case, the BPR is 2.0-2.5 times superior to the strength characteristics of steel reinforcement and is not subject to corrosion. Complex BPR tests were conducted in the laboratories of the National Aviation University (Figures 10 and 11).

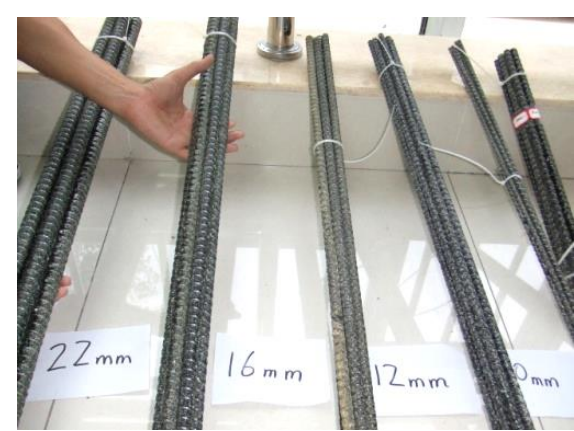

Figure 10. Basalt-plastic reinforcement (BPR) of different diameters of $10-22 \mathrm{~mm}$

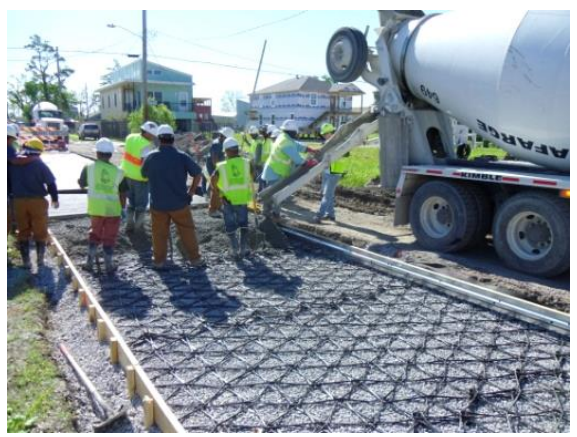

Figure 11. Application of BPR in the construction of airfield concrete pavement

Table 4 shows the results of studies on the replacement of steel reinforcement with composite $\mathrm{BCF}$ reinforcement.

Table 4. Test results of steel and composite reinforcement

\begin{tabular}{|c|c|c|c|c|}
\hline \multicolumn{4}{|c|}{ Equal strength replacement of steel reinforcement A III with BPR } \\
\hline \multirow{2}{*}{ No. } & \multicolumn{2}{|c|}{ Composite reinforcement BPR } & \multicolumn{2}{c|}{ Steel reinforcement A III } \\
\cline { 2 - 5 } & BPR diameter, mm & $\begin{array}{c}\text { number of running meters in } \\
\text { tons of reinforcement }\end{array}$ & AIII, diameter, mm & $\begin{array}{c}\text { number of running meters in } \\
\text { tons of reinforcement }\end{array}$ \\
\hline 1 & ABP-4 & 48780 & A III -4 & 4504 \\
\hline 2 & ABP-6 & 20618 & A III -6 & 2531 \\
\hline 3 & ABP-8 & 11299 & A III -8 & 1620 \\
\hline 4 & ABP-10 & 7092 & A III -10 & 1126 \\
\hline 5 & ABP-12 & 4897 & A III - 12 & 826 \\
\hline 6 & ABP-14 & 3788 & A III -14 & 405 \\
\hline
\end{tabular}

For tunnels mounting special anchors with openings are developed, which are shown in Figures 12 and 13.

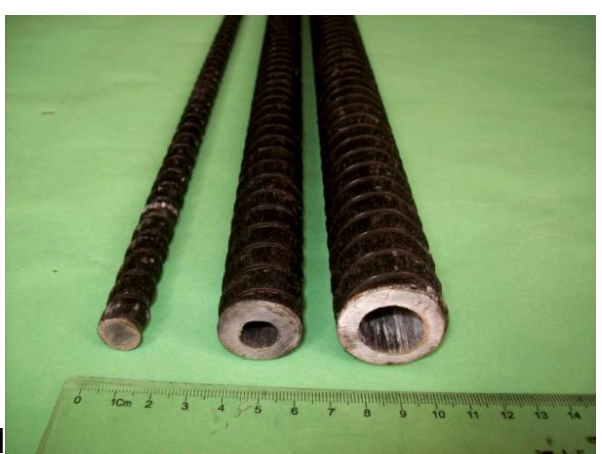

Figure 12. Hollow anchors for tunnels mounting

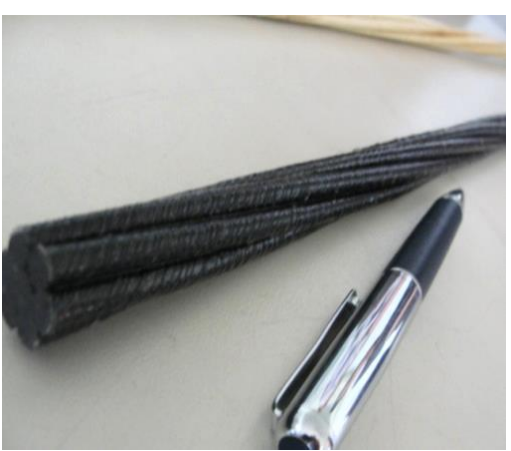

Figure 13. Composite cable rope from BCF 
Composite materials, due to their characteristics and cost, are actively replacing steel materials in the engineering and other industries. Therefore, the widespread use of composite materials and products in road and airfield construction is also an urgent task. To date, a number of composite materials and products based on BCF for road construction have already been designed, manufactured, and are being used: composite cables for cable-stayed bridges, lighting supports, collector housings, road signs, bumpers, limiters, manhole covers and underground communications.

\section{Conclusions}

The following conclusions can be drawn from the research and experimental work carried out on the development and application of BCF-based geotextile materials:

- BCF is a good substitute for reinforcing materials made of metal, chemical fibers and fiberglass, as they have high strength, chemical and thermal strength, are not stretched under load, durable in operation;

- Particularly high resistance is shown by reinforcing materials made of basalt fibers in acidic and alkaline environments, under the influence of the environment, which opens great prospects for their use for reinforcing concrete runways at airfields;

- use of geotextile reinforcing materials made of continuous and basalt fibers allows creating the reinforced structures of road and airfields, slopes, embankments, to provide high quality of performed repair works;

- use of geotextile materials based on basalt fibers has a great potential for use in the practice of road, airfield, hydrotechnical construction.

\section{References}

Dzihigiris, D. D., \& Mahova, M. F. (2002). Osnovy proizvodstva bazaltovyh volokon i izdelij: monografiya. Teplojenergetik (in Russian).

Ferrotti, G., Pasquini, E., \& Canestari, F. (2014). Experimental characterization of high-performance fiber-reinforced cold mix asphalt mixtures. Construction and Building Materials, 57, 117-125. https://doi.org/10.1016/j.conbuildmat.2014.01.089

Füssl, J., Kluger-Eigl, W., \& Blab, R. (2015a). Mechanical performance of pavement structures with paving slabs - Part I: fullscale accelerated tests as validation for a numerical simulation tool. Engineering Structures, 98, 221-229.

Füssl, J., Kluger-Eigl, W., Eberhardsteiner, L., \& Blab, R. (2015b). Mechanical performance of pavement structures with paving slabs - Part II: numerical simulation tool validated by means of full-scale accelerated tests. Engineering Structures, 98, 221-229. https://doi.org/10.1016/j.engstruct.2014.10.055

Gameliak, I., Zhurba, G., \& Kostryckyy, V. (2010). Determination of geosynthetic materials resistance to cyclic loading. In 9 th International Conference on Geosynthetics (pp. 631-634), Brazil.

Gamelyak, I. (2001). The effect of destruction on the change in strength of pavement structures. Autom. Roads and Dor., 62, 157-165.

Kokodeeva, N. (2014). To determine the service life of pavement with geosynthetic materials, Roads. Innovation in Construction, $34,26-29$.

Korolev, M. (1994). Use of geosynthetics in pavement designs. In 2nd International Congress on Geotextiles (pp. 8-9), Las Vegas, USA.

Krayushkina, E. V. (2001). Determination of the operational state of surfaces intended for pedestrian traffic. Automobile Roads and Roads Budivnistvo, 62, 33-35.

Krayushkina, E. V., Vyrozhemsky, V. K., \& Chimerik, T. Y. (2005). Improving crack resistance and roughness of road surfaces by using bitumen-polymer compositions. Reliability problems of pavement on city streets and roads: Proceedings of the International Scientific and Practical Conference (pp. 187-194), Minsk.

Krayushkina, E., \& Belyatynsky, A. (2013). Application of three-dimensional geogrids for stabilization of waterlogged soils in Ukraine. Roads, 25, 50-52.

Krayushkina, E., \& Khimerik, T. (1998). Basalt fiber-reinforced layers for reinforcing the carriageway and roadsides. In Zbirnik, "The Ukrainian Road Complex in Today's Minds: Problems and Development Hats" (pp. 229-231). Kyiv.

Krayushkina, K., Prentkovskis, O., Bieliatynskyi, A., \& Junevicius, R. (2012). Use of steel slags in automobile road construction. Transport, 27(2), 129-137. https://doi.org/10.3846/16484142.2012.690093

Moskaleva, O. (2014). On the effect of a composite layer based on geo-cellular material on the operation of pavement. Roads and Bridges, 32/4, 55-69.

Mueller-Rochholz, J. (2010). Long term performance of geosynthetics. In 9th International Conference on Geosynthetics (pp. 455-461), Brazil.

Tapkin, S., \& Özcan, S. (2012). Determination of the optimal polypropylene fiber addition to the dense bituminous mixtures by the aid of mechanical and optical means. The Baltic Journal of Road and Bridge Engineering, 7(1), 22-29. https://doi.org/10.3846/bjrbe.2012.03

Wilmers, V., \& Veplar, N. (1994). Instructions for the use of geotextiles and geogrids in road construction. MADI.

Ye, H., \& Li, S. (2016). The imitation of the road surface temperature variation characteristics subjected to periodical ambient conditions. Applied Thermal Engineering, 92, 194-201. https://doi.org/10.1016/j.applthermaleng.2015.09.086 